\title{
Magnetic resonance angiographic and clinical features of extracranial vertebral artery dissection
}

\author{
A Auer, S Felber, C Schmidauer, P Waldenberger, F Aichner
}

\begin{abstract}
Objectives-Clinical data and neuroradiological findings of 19 patients with 20 vertebral artery dissections were analysed to describe the features of time of flight magnetic resonance angiography (MRA) for the diagnosis and follow up of this vascular disorder.
\end{abstract}

Methods-All patients underwent a combined MRI and MRA protocol with $1.5 \mathrm{~T}$ scanners, using a three dimensional flow compensated gradient echo sequence for MRA. Duplex sonography was performed on all patients and selective angiography was available from 17 vertebral artery dissections.

Results-MRI showed ischaemic lesions of the brain in 18 of 19 patients (95\%). In the acute and subacute stage, MRA detected signal abnormalities within the dissected vertebral artery in $94 \%(16 / 17)$ and MRI was specific for a dissection in $29 \%$ (5/17). Sensitivity of selective angiography was $100 \%$ and specificity was $35 \%(6 / 17)$. Combination of the results of both methods increased the specificity to $50 \%$. Duplex sonography was sensitive in $\mathbf{7 9 \%}$ (15/19), but lacked specific results. Follow up magnetic resonance in 16 patients showed recanalisation of the dissected vessel in $10(63 \%)$, persistent occlusion in five $(31 \%)$, and a dissecting aneurysm in one $(6 \%)$ patient.

Conclusions-Magnetic resonance improves the triage for selective angiography and discloses complementary information for the diagnosis of vertebral artery dissection. If magnetic resonance identifies a double lumen or a mural haematoma with a stenosis or aneurysmal dilatation, invasive procedures can be omitted.

(F Neurol Neurosurg Psychiatry 1998;64:474-481)

Keywords: vertebral artery dissection; angiography; magnetic resonance angiography; ultrasound

Vertebral artery dissection is an increasingly recognised cause of posterior circulation stroke in young and middle aged adults. ${ }^{1-3}$ The most frequent symptoms include unilateral neck pain $^{45}$ that may be followed by transient or permanent ischaemia of vertebrobasilar tributaries of the brain. ${ }^{6}$ Vertebral artery dissection may lead to stroke or even death. ${ }^{7}$ Although placebo controlled studies on the treatment of vertebral artery dissection are missing, some authors suggest that early anticoagulation can prevent thrombembolic complications. ${ }^{148-10}$
Selective digital subtraction angiography (DSA) is still considered the "gold standard" for the diagnosis of vertebral artery dissection, ${ }^{14511-14}$ but is not always definitive in the diagnosis of the disease. ${ }^{12}$ As DSA is not without risk, ${ }^{15}{ }^{16}$ many clinicians hesitate to submit patients to this technique until obvious neurological symptoms are present. This underlines the need for a non-invasive method to support the diagnosis of vertebral artery dissection to improve the selection of patients for DSA or even to replace the invasive procedure.

This aim has been approached in the diagnosis of carotid artery dissection, in which the non-invasive procedures ultrasound and MRI play an increasing part ${ }^{14}{ }^{17-22}$ and in which magnetic resonance angiography (MRA) is already in competition with DSA. ${ }^{82}$ In vertebral artery dissection, several studies have focused on the visualisation of a mural and luminal thrombus on routine spin echo (SE) images. ${ }^{7}{ }^{102-26}$ More recently, MRA has been applied in patients with vertebral artery dissection, ${ }^{23}{ }^{27}$ but the results were not as straightforward as in carotid artery dissection, because of the smaller lumen and physiological variations in the diameter of the vertebral artery. ${ }^{23}$

Here, we report on the results of combined MRI and MRA examinations of 20 vertebral artery dissections, based on a retrospective analysis of the clinical and neuroradiological findings in 19 patients.

\section{Patients and methods}

Between 1989 and 1995 we identified 19 patients (seven women and 12 men; mean age 39.5 (range 23 to 60 ) years) who had had a vertebral artery dissection and in whom MRI/ MRA examinations had been performed. The diagnosis was either based on characteristic DSA features or was confirmed by clinical presentation and course, presumptive neuroradiological findings, and the results of follow up examinations. Eighteen patients presented with a unilateral and one with a simultaneous bilateral vertebral artery dissection.

At presentation, all patients had neurological symptoms. Twelve patients $(63 \%)$ had a history of a preceding neck or head trauma, most of which were minor. Initial symptoms, such as neck pain, headache, and vertebrobasilar transient ischaemic attacks were found in 12 patients $(63 \%)$. These symptoms preceded the onset of the ischaemic deficit of the vertebrobasilar territory for up to two weeks. Neurological deficits persisted in 10 patients (53\%) (table 1).

All patients underwent an initial CT examination on a fourth generation scanner 
Table 1 Clinical and parenchymal MRI findings in 19 patients with extracranial VADs

\begin{tabular}{|c|c|c|c|c|c|c|}
\hline $\begin{array}{l}\text { Patient } \\
\text { No/sex/ } \\
\text { age }\end{array}$ & Predisposing factors & Initial symptoms & Neurological signs & Infarct territory & Treatment & Outcome \\
\hline $1 / \mathrm{M} / 32$ & Fall & Neck pain (ipsilateral), headache & $\begin{array}{l}\text { Hemiparesis, dysarthria, } \\
\text { hemianopia }\end{array}$ & PCA, thalamus & Heparin, aspirin & Clinical recovery \\
\hline $2 / \mathrm{M} / 41$ & - & Neck pain (ipsilateral) & Wallenberg syndrome & PICA, bilateral & $\begin{array}{l}\text { Heparin, } \\
\text { dipyramidol }\end{array}$ & $\begin{array}{l}\text { Dysarthria, } \\
\text { dysphagia }\end{array}$ \\
\hline $3 / \mathrm{M} / 37$ & Smoking & Vertebrobasilar TIAs & Wallenberg syndrome & PICA & $\begin{array}{l}\text { Heparin, } \\
\text { coumarin }\end{array}$ & Clinical recovery \\
\hline $4 / \mathrm{F} / 44$ & Fall & - & Cerebellar ataxia, dysarthria & $\begin{array}{l}\text { PICA, bilateral, } \\
\text { AICA }\end{array}$ & Heparin, aspirin & Ataxia \\
\hline $5 / \mathrm{M} / 40$ & Skiing & Neck pain (bilateral) & $\begin{array}{l}\text { Wallenberg syndrome, } \\
\text { hemiparesis }\end{array}$ & PICA & $\begin{array}{l}\text { Heparin, } \\
\text { coumarin }\end{array}$ & Hemiparesis \\
\hline $6 / \mathrm{F} / 30$ & $\begin{array}{l}\text { Skiing, migraine, oral } \\
\text { contraceptive }\end{array}$ & Neck pain (ipsilateral) & Locked in syndrome & Pontin & $\begin{array}{l}\text { Heparin, } \\
\text { coumarin }\end{array}$ & $\begin{array}{l}\text { Tetraparesis, } \\
\text { dysarthria }\end{array}$ \\
\hline 7/M/59 & Hypertension & - & $\begin{array}{l}\text { Hemiataxia, dysarthria, } \\
\text { diplopia, nystagmus }\end{array}$ & Pontin (small) & Aspirin & Clinical recovery \\
\hline $8 / \mathrm{M} / 51$ & Hypertension & $\begin{array}{l}\text { Neck pain (ipsilateral), headache, } \\
\text { vertebrobasilar TIAs }\end{array}$ & $\begin{array}{l}\text { Paraparesis, nystagmus, } \\
\text { diplopia }\end{array}$ & Pontin (small) & $\begin{array}{l}\text { Heparin, } \\
\text { coumarin }\end{array}$ & Clinical recovery \\
\hline $9 / \mathrm{M} / 41$ & Fall & Headache, vertebrobasilar TIAs & Hemiataxia, hemianopia & PCA, AICA & Heparin, aspirin & Clinical recovery \\
\hline $10 / \mathrm{M} / 40$ & Fall, smoking & Headache & Hemiataxia, dysarthria & PICA, AICA & Heparin, aspirin & Clinical recovery \\
\hline $11 / \mathrm{F} / 36$ & Fall, smoking & Headache & Hemiparesis & None & $\begin{array}{l}\text { Ligature, } \\
\text { aspirin }\end{array}$ & Clinical recovery \\
\hline $12 / \mathrm{M} / 32$ & Smoking & Neck pain (ipsilateral), headache & $\begin{array}{l}\text { Wallenberg syndrome, } \\
\text { diplopia }\end{array}$ & PICA & Heparin, aspirin & Hemihypaesthesia \\
\hline $13 / \mathrm{F} / 32$ & $\begin{array}{l}\text { Fall, smoking, oral } \\
\text { contraceptive }\end{array}$ & - & $\begin{array}{l}\text { Wallenberg syndrome, } \\
\text { diplopia }\end{array}$ & PICA & Heparin, aspirin & Clinical recovery \\
\hline $14 / \mathrm{F} / 60$ & Hypertension & Vertebrobasilar TIAs & Wallenberg syndrome & PICA & $\begin{array}{l}\text { Coumarin, } \\
\text { aspirin }\end{array}$ & Hemiataxia \\
\hline $15 / \mathrm{M} / 23$ & Surfing & - & Somnolence, tetraparesis & Pontine (small) & Heparin, aspirin & Clinical recovery \\
\hline $16 / \mathrm{F} / 35$ & Horse riding & - & $\begin{array}{l}\text { Somnolence, hemiataxia, } \\
\text { hemiparesis }\end{array}$ & PCA, thalamus & $\begin{array}{l}\text { Aspirin, VA } \\
\text { ligation }\end{array}$ & $\begin{array}{l}\text { Ataxia, } \\
\text { hemihypaesthesia }\end{array}$ \\
\hline $17 / \mathrm{M} / 36$ & Hypertension, smoking & - & Wallenberg syndrome & PICA & Heparin, aspirin & Hemiataxia \\
\hline $18 / \mathrm{M} / 47$ & $\begin{array}{l}\text { Abrupt head turning, } \\
\text { smoking }\end{array}$ & - & $\begin{array}{l}\text { Wallenberg syndrome, } \\
\text { hemiparesis }\end{array}$ & PICA & $\begin{array}{l}\text { Heparin, } \\
\text { pentaxifyllin }\end{array}$ & $\begin{array}{l}\text { Dysarthria, } \\
\text { hemihypaesthesia }\end{array}$ \\
\hline $19 / F / 36$ & Fall & Headache, vertebrobasilar TIAs & Hemiparesis & PCA, thalamus & $\begin{array}{l}\text { Heparin, } \\
\text { coumarin }\end{array}$ & Hemihypaesthesia \\
\hline
\end{tabular}

MRI = magnetic resonance imaging; VAD = vertebral artery dissection; TIA = transient ischaemic attack; $M=$ male; $F=$ female; VA = vertebral artery; PICA = posterior inferior cerebellar artery; AICA = anterior inferior cerebellar artery; PCA = posterior cerebral artery.

(Somatom Plus, Siemens, Germany) including $4 \mathrm{~mm}$ slices through the posterior fossa.

Intra-arterial angiography (Philips ACR, Best, The Netherlands) was performed via the transfemoral route with selective contrast injection into the vertebral arteries or the respective subclavian arteries employing plain film or digital subtraction techniques within three weeks of onset of the neurological deficit in 16 patients (17 vertebral artery dissections, 12 within the first week). Follow up examinations (three weeks to two months) were available in two patients. Intimal flaps, double lumen, and dissecting aneurysms were rated specific; irregular stenosis (string sign) was considered suggestive of vertebral artery dissection.

Duplex sonography (Spectra VST, Diasonics, Santa Clara, USA) was performed in all patients; within three weeks of the onset of the neurological deficit in 18 patients (19 vertebral artery dissections, 15 within the first week). The results were documented as flow velocity, flow direction, and waveform characteristics of the extracranial and intracranial vertebral artery. A high resistance signal (HRS) in the vertebral artery was diagnosed if no diastolic flow was evident in the Doppler signal, combined with the characteristic acoustic quality of the signal. ${ }^{28}$

Examinations with MRI/MRA were performed within two weeks of the onset of neurological deficit in 16 patients (17 vertebral artery dissections, five within the first 24 hours). Follow up examinations (10 days to four years, including first investigations in the chronic stage in three patients) were available in 16 patients. Most initial MRI/MRA examinations (16 patients, 17 vertebral artery dissections) were performed on a $1.5 \mathrm{~T}$ scanner (Magnetom, Siemens, Erlangen, Germany) equipped with a $10 \mathrm{mT} / \mathrm{m}$ gradient system. The follow up examinations were done on a $1.5 \mathrm{~T}$ scanner (Vision, Siemens, Erlangen; Germany) equipped with a $23 \mathrm{mT} / \mathrm{m}$ gradient system. On both scanners, we employed circular polarised head coils and SE sequences for T1 ( $\mathrm{TR}=550 \mathrm{~ms} / \mathrm{TE}=15 \mathrm{~ms}$ ), proton density (PD) and T2 weighted images (WI) $(\mathrm{TR}=2400$ $\mathrm{ms} / \mathrm{TE}=15 / 90 \mathrm{~ms}$ ) in at least two orthogonal orientations. For MRA of the intracranial arteries we used a time of flight (TOF) sensitive three dimensional fast Fourier transformation (3D FFT) gradient echo sequence (FISP - fast imaging with steady state precession: $T R=40$ $\mathrm{ms}, \mathrm{TE}=6-8 \mathrm{~ms}, \alpha=15^{\circ}$ ) with incorporated gradient moment nulling in slice select and read out direction for constant velocities. ${ }^{29} 30$ The tilted transverse excitation slab (1 mm partitition thickness, $0.9^{\star} 0.9 \mathrm{~m}$ in plane resolution) included the V4 segments of the vertebral arteries, the basilar artery, the posterior inferior cerebellar arteries, the anterior inferior cerebellar arteries, the superior cerebellar arteries, the posterior communicating arteries, and the posterior cerebral arteries as well as parts of the anterior circulation. The extracranial neck arteries were imaged with a 3D FLASH (fast low angle shot imaging: $\mathrm{TR}=50 \mathrm{~ms}, \mathrm{TE}=8 \mathrm{~ms}, \alpha=20^{\circ}$ ) sequence, flow compensated in slice select and readout direction. The coronal 3D volume included both 
Table 2 MRI/MRA, DSA, and duplex sonographic findings in 19 patients with extracranial VADs

\begin{tabular}{|c|c|c|c|c|c|c|c|}
\hline $\begin{array}{l}\text { Patient } \\
\text { No }\end{array}$ & $V A D$ & $\begin{array}{l}\text { Delay } \\
\text { (days) }\end{array}$ & $M R I$ & $M R A$ & $D S A$ & Duplex & $M R A$ follow up (delay) \\
\hline 1 & $\mathrm{~L}$ & 6 & Mural haematoma V3 & Stenosis V3-4 & String sign V3 & HRS & $\begin{array}{l}\text { Pseudoenlargment }{ }^{\star \star} \text { (14 days), } \\
\text { recanalisation (12 months) }\end{array}$ \\
\hline 2 & $\mathrm{R}$ & & - & - & String sign V3 & - & Recanalisation ( 3 months) \\
\hline 3 & $\mathrm{~L}$ & $<1$ & $\begin{array}{l}\text { Mural haematoma V3, } \\
\text { luminal thrombis V4 }\end{array}$ & Stenosis V3 & String sign V3, occlusion V4 & HRS & Occlusion (> 12 months) \\
\hline 4 & $\mathrm{~L}$ & 7 & Normal V3-4 & Normal V2-4 & Intimal flap V1 & Normal & Normal (12 months) \\
\hline 5 & $\mathrm{~L}$ & $<1$ & Luminal thrombus V4 & $\begin{array}{l}\text { Occlusion V1, V4, stenosis } \\
\text { V2-3 }\end{array}$ & Occlusion VA L & HRS & Recanalisation ( 2 weeks) \\
\hline 6 & $\mathrm{R}, \mathrm{L}$ & 14 & Luminal thrombus BA & $\begin{array}{l}\text { Stenosis V3-4 R, L, occlusion. } \\
\text { BA (delay to DSA } 14 \text { day) }\end{array}$ & $\begin{array}{l}\text { Double lumen V1 L, string } \\
\text { sign V2-4 R, occlusion BA }\end{array}$ & $\begin{array}{l}\text { No flow } \\
\mathrm{L}, \mathrm{R}\end{array}$ & - \\
\hline 7 & $\mathrm{~L}$ & 5 & Luminal thrombus V3-4 & Stenosis V2, occlusion V3-4 & - & HRS & Recanalisation (> 12 months) \\
\hline 8 & $\mathrm{R}$ & 3 & Luminal thrombus V4 & Stenosis V3, occlusion V4 & - & HRS & Recanalisation ( 8 months) \\
\hline 9 & $\mathrm{R}$ & $<1$ & Luminal thrombus V3-4 & Stenosis V2, occlusion V3-4 & $\begin{array}{l}\text { String sign V2-3, occlusion } \\
\text { V4 }\end{array}$ & HRS & Recanalisation (3 months) \\
\hline 10 & $\mathrm{R}$ & 3 & Luminal thrombus V4 & Stenosis V2-3, occlusion V4 & - & HRS & Occlusion (> 12 months) \\
\hline 11 & $\mathrm{~L}$ & & - & - & $\begin{array}{l}\text { Intimal flap V2, dissecting } \\
\text { aneurysm V2 }\end{array}$ & Normal & $\begin{array}{l}\text { Occlusion ( } 9 \text { months after } \\
\text { ligation) }\end{array}$ \\
\hline 12 & $\mathrm{~L}$ & $<1$ & Luminal thrombus V3-4 & $\begin{array}{l}\text { Double lumen V2, occlusion } \\
\text { V3-4 }\end{array}$ & $\begin{array}{l}\text { String sign V2, occlusion } \\
\text { V3-4 (delay to MRA } 1 \text { day) }\end{array}$ & HRS & Recanalisation (9 months) \\
\hline 13 & $\mathrm{R}$ & 5 & Luminal thrombus V3-4 & Occlusion V3-4 & Stenosis V4 & HRS & Recanalisation (12 months) \\
\hline 14 & $\mathrm{~L}$ & 7 & Luminal thrombus V3-4 & Stenosis V2, occlusion V3-4 & Occlusion V3-4 L & HRS & Recanalisation (> 12 months) \\
\hline 15 & $\mathrm{R}$ & 7 & Luminal thrombus V3-4 & Occlusion V2-4 & $\begin{array}{l}\text { Intimal flap V1, occlusion } \\
\text { V2-4 }\end{array}$ & No flow & Occlusion (> 12 months) \\
\hline 16 & $\mathrm{R}$ & & - & - & $\begin{array}{l}\text { Intimal flap V1, dissecting } \\
\text { aneurysm V1 }\end{array}$ & Normal & $\begin{array}{l}\text { Occlusion ( } 5 \text { months after } \\
\text { ligation) }\end{array}$ \\
\hline 17 & $\mathrm{~L}$ & 7 & $\begin{array}{l}\text { Mural haematoma V3, } \\
\text { luminal thrombus V4 }\end{array}$ & Stenosis V3, occlusion V4 & String sign V3, occlusion V4 & HRS & - \\
\hline 18 & $\mathrm{R}$ & 5 & Luminal thrombus V3-4 & Occlusion V3-4 & String sign V3, occlusion V4 & HRS & - \\
\hline 19 & $\mathrm{~L}$ & $<1$ & Mural haematoma V3 & $\begin{array}{l}\text { Stenosis V3, dissecting } \\
\text { aneurysm V3 }\end{array}$ & $\begin{array}{l}\text { String sign V3, dissecting } \\
\text { aneurysm V3 }\end{array}$ & Normal & Dissecting aneurysm (2 weeks) \\
\hline
\end{tabular}

* Delay $=$ interval from neurological deficit to magnetic resonance examination.

$\star \star$ Pseudoenlargement $=$ on projections the dissected vertebral artery appears wider than the patent lumen on cross sections.

MRI = magnetic resonance imaging; $\mathrm{MRA}=$ magnetic resonance angiography; DSA = digital subtraction angiography; Duplex = B-mode and Doppler sonography; $\mathrm{VAD}=$ vertebral artery dissection; delay $=$ interval from neurological deficit to magnetic resonance examination; HRS = high resistance signal; string sign = irregular stenosis; $\mathrm{L}=$ left; $\mathrm{R}=$ right; $\mathrm{V} 1-4$ = vertebral artery segment; $\mathrm{BA}=$ basilar artery.

carotid arteries and V2-4 segments of the vertebral arteries; the aortic arch and the origin of the vertebral arteries were not within the excitation volume. The images were reconstructed using a maximum intensity projection (MIP) algorithm, to render projection $\mathrm{MR}$ angiograms from different viewing angles. If the vertebral artery was not adequately delineated on the projections or the source images, additional 2D TOF sensitive FLASH images ( $\mathrm{TR}=60 \mathrm{~ms}, \mathrm{TE}=9 \mathrm{~ms}, \alpha=30^{\circ}$ ) were obtained.

Signal abnormalities of the displayed vertebral artery were rated on SE images together with MRA projections and partitions and the additional FLASH images. Occlusion referred to non-visualisation of flow on either sequence. Criteria for a mural haematoma were an eccentric residual lumen surrounded by a
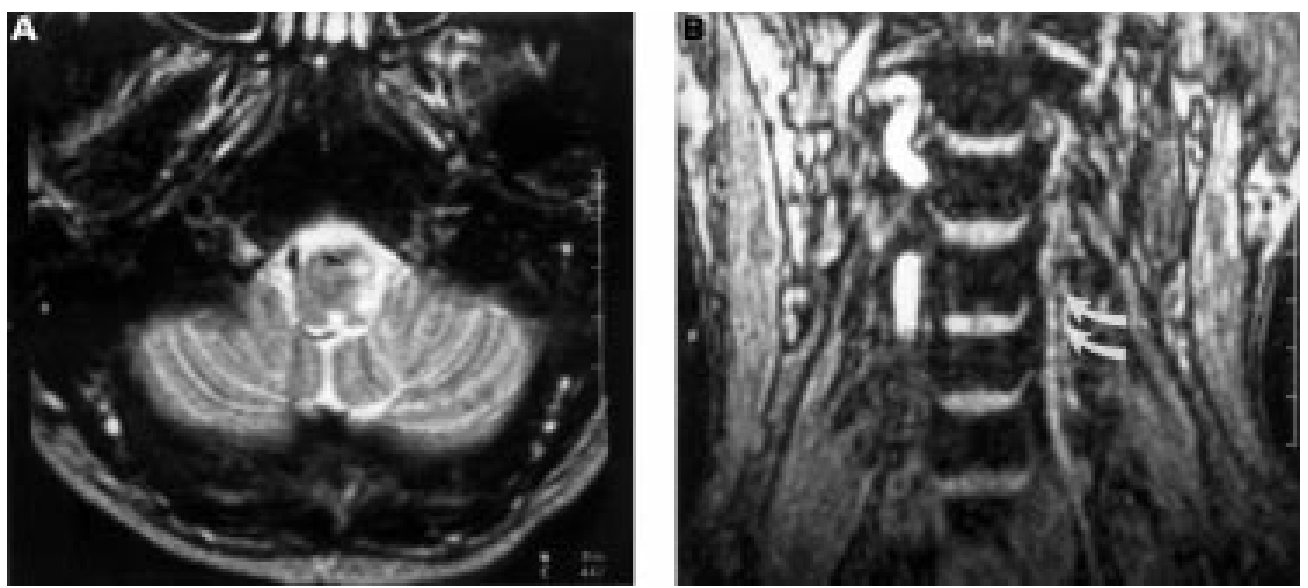

Figure 1 Patient 12 with left sided neck pain and headache followed by acute onset of left sided Wallenberg syndrome. The axial T2 weighted image $(A)$ shows a hyperintense lesion in the left dorsolateral medulla oblongata (arrow). The coronal $M R A$ source image (B) shows a double lumen of the V2 segment of the left vertebral artery (arrows). 
anterior inferior cerebellar artery infarcts), cortical posterior cerebral artery infarcts in four patients (three also had infarctions of the thalamus and one of the anterior inferior cerebellar artery territory), and pontine infarctions in four (table 1).

The MRA projections were interpreted together with the source images and the SE images of the appropriate levels, if available. The findings were correlated with the time delay between the clinical onset of symptoms and the MR examinations (table 2).

MRI/MRA FINDINGS UP TO 24 HOURS AFTER ONSET OF NEUROLOGICAL DEFICIT

This group consists of five patients who underwent MRI/MRA before DSA. The delays between DSA and MRI/MRA ranged between
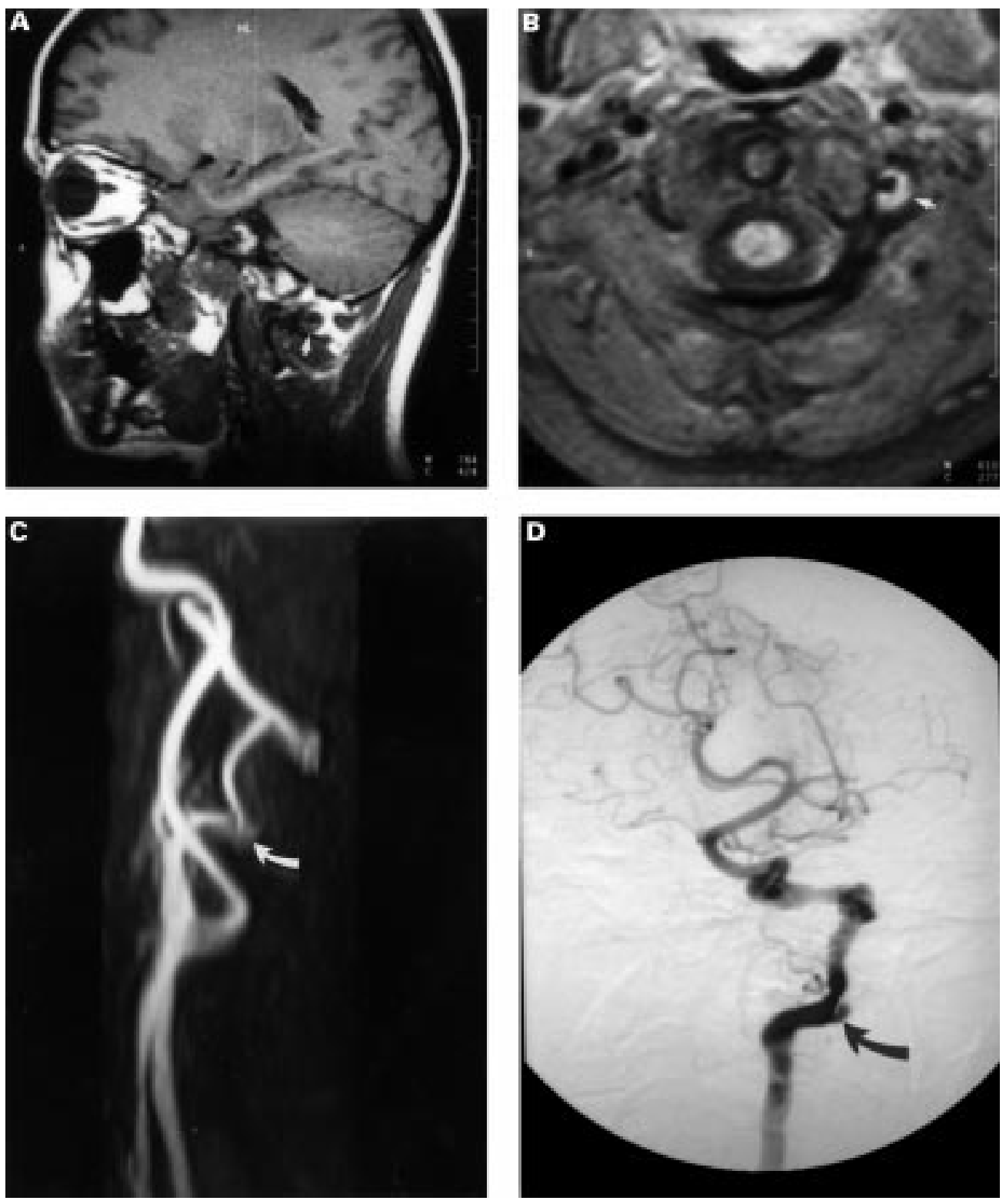

Figure 2 Patient 19 with a preceeding minor neck trauma, left sided headache, and a transient ischaemic attack three days before onset of right sided hemiparesis. The sagittal T1 weighted image $(A)$ shows a mural haematoma of isointense signal (arrow) with eccentric residual lumen (signal void) of the left vertebral artery at the V3 segment. The mural haematoma is better visualised on the fat suppressed T1 weighted image (B) with slice selective radiofrequency presaturation to avoid arterial and venous inflow. This technique provides the differentiation of the mural haematoma (arrow) from surrounding fat tissue and flow signal in the adjacent venous plexus. The MRA (C) shows a dissecting aneurysm (arrow). Digital subtraction angiography (D) one day later also showed the dissecting aneurysm (arrow). 

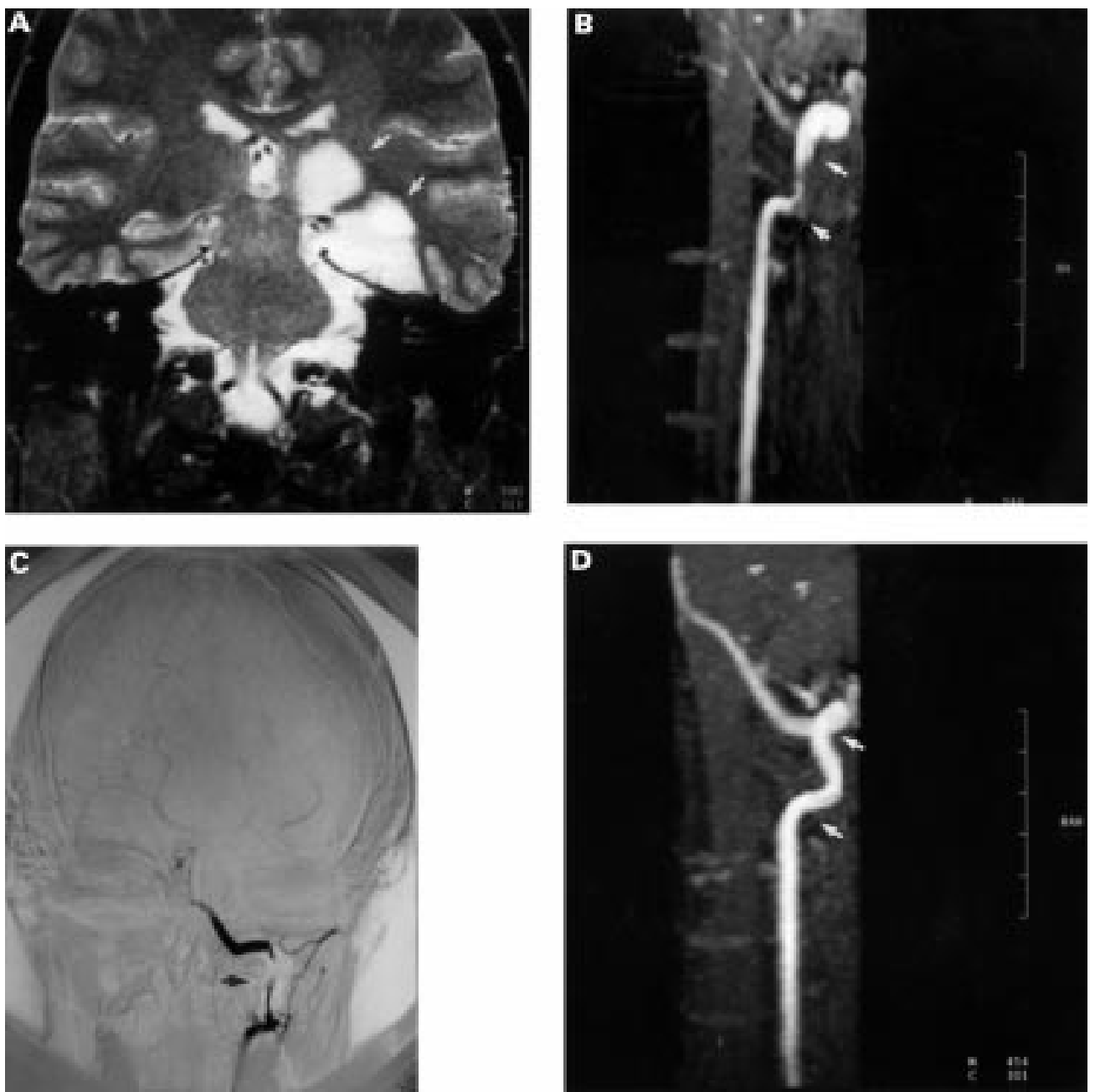

Figure 3 Patient 1 with right sided hemiparesis, hemianopia, and dysarthria had had a minor trauma and left sided neck pain and occipital headache one week previously. The coronal T2 weighted image (A) shows a hyperintense ischaemic lesion in the left posterolateral thalamus and occipital cortex. The MRA projection (B) shows a pseudoenlargement (arrows) of the V3 segment of the left vertebral artery due to the presence of methaemoglobin. The DSA (C) shows irregular stenosis at the comparable level (arrow). The follow up MRA (D) four years later displays recanalisation of the stenotic V3 segment (arrows).

lumen of the V2 segment on MRA; 17 hours later DSA showed a string sign at that level (fig 1). Patient 19 showed a stenosis and an aneurysmal dilatation of the V3 segment on the MRA projections and a mural haematoma at the coincident level that was isointense on T1WI, hyperintense on PDWI, hypointense on T2WI, and isointense on the MRA source images, best seen on the fat suppressed T1WI (fig 2). Digital subtraction angiography one day later showed a string sign and an aneurysmal dilatation of the V3 segment (fig 2).

MRI/MRA FINDINGS ONE DAY UP TO TWO WEEKS AFTER ONSET OF NEUROLOGICAL DEFICIT

This group consisted of 11 patients. The delays between DSA and MRI/MRA ranged between several hours up to 14 days; two patients underwent MRI/MRA before DSA and three patients had no DSA. In four patients $(7,13$, 14, 18 ) the V3-4 segments appeared occluded on MRI/MRA, two of them had residual flow of the V2 segment. Digital subtraction angiography was available in three of these patients, and showed corresponding findings in two of them $(14,18)$, and a stenosis of the V4 segment

in patient 13 . Three patients $(8,10,17)$ had an occlusion of the V4 segment with luminal thrombus on MRI/MRA, and a stenosis of the proximal V2-3 segments. These findings correlated with DSA in patient 17 , who additionally displayed a mural haematoma on MRI/MRA at the V3 level, that was hyperintense on either sequence. Patient 1 had a stenosis of the V3-4 segments, which was equally present on DSA and MRA. In addition there was a mural haematoma at the V3 level that was isointense on T1WI, hyperintense on PDWI, hypointense on T2WI, and isointense on MRA source images. Patient 4 had an intimal flap of the V1 segment on DSA, but was rated normal on MRI/MRA, because the V1 segment was not included within the examination volume. Patient 6 displayed an occlusion with luminal thrombus of the distal basilar artery and stenosis of the V3-4 segments of both vertebral arterys on MRI/MRA. Digital subtraction angiography showed a double lumen of the V1 segment in the left vertebral artery and a string sign of the V2-4 segments in the contralateral vertebral artery in addition to an occlusion of the basilar artery 14 days before MRI/MRA. In 
patient 15, MRI/MRA disclosed an occlusion of the V2-4 segments with a luminal thrombus, but failed to show an intimal flap of the V1 segment established by DSA.

The sensitivity and specificity of MRI/MRA, DSA, and ultrasound during the acute and subacute phase after vertebral artery dissection were correlated with the final diagnosis. For abnormal flow in the vertebral artery the sensitivity was $79 \%$ (15/19 vertebral artery dissections) for duplex sonography, 100\% (17/17 vertebral artery dissections) for DSA, and 94\% (16/17 vertebral artery dissections) for MRA. Ultrasound was normal in four patients, three of them displayed intimal flaps of the V1 and V2 segments on DSA and one a string sign on MRA. There was one false negative MRI/MRA result in a patient who had an isolated intimal flap of the V1 segment on DSA. Digital subtraction angiography showed specific findings in 35\% (6/17 vertebral artery dissections; intimal flap four, double lumen one, dissecting aneurysm one). Three of them had no MRI/MRA within a corresponding time interval, in two patients the pathognomonic features were not within the MR examination volume, and in one patient MRI/MRA was also specific for vertebral artery dissection. MRI/MRA disclosed findings that were rated specific in $29 \%$ (5/17 vertebral artery dissections; mural haematoma in combination with stenosis three, mural haematoma in combination with aneurysmal dilatation one, double lumen one). Digital subtraction angiography disclosed a string sign in four of them, and in one patient DSA showed a dissecting aneurysm, which was also seen on MRA. If DSA and MRI/MRA results were combined for the 20 vertebral artery dissections, the specificity for dissection increased to $50 \%$.

MRI/MRA FOLLOW UP EXAMINATIONS

This group consists of 16 patients, including three $(2,11,16)$, who had their first MR examination in the chronic stage after dissection. MRI/MRA showed recanalisation of the dissected vertebral artery in $63 \%(10 / 16$; fig 3$)$, persistent occlusion in $31 \%$ (5/16, including patient 11 and 16, who developed DSA established dissecting aneurysms after vertebral artery dissection that had been surgically ligated before MRI/MRA), and a dissecting aneurysm in $6 \%$. Among the three patients in whom no DSA was performed, two vertebral arteries had recanalised, and one vertebral artery (patient 10 with adequate trauma) remained occluded.

\section{Discussion}

More than 100 cases of vertebral artery dissection have been reported in the past two decades ${ }^{13}$ and today it is accepted that it is not a rare cause of vertebrobasilar stroke in the younger population. Patients with a benign natural course of vertebral artery dissection may not undergo DSA at all and remain undiagnosed. This indicates that the incidence might be higher than presently considered. Vertebral artery dissection was associated with a good prognosis in some reports, ${ }^{24} 51233$ how- ever, posterior circulation stroke is not uncommon and $53 \%$ of our patients have permanent neurological deficits. In our series and previous reported clinical studies ${ }^{7}$ most patients experienced minor symptoms such as neck pain or even transient ischaemic attacks, before established neurological deficit prompted neuroradiological examination and diagnosis.

Selective DSA and CT are commonly employed as the initial neuroradiological investigation in patients with suspected vertebral artery dissection. CT has the major role to rule out other sources of neurological symptoms and usually fails to detect early ischaemia within the posterior fossa. Digital subtraction angiography results remain non-specific, unless a double lumen, an intimal flap, ${ }^{34-36}$ or a dissecting aneurysm ${ }^{12}$ is present. Irregular stenosis (string sign) and occlusion are not more than indirect manifestations of changes in the arterial wall by a mural haematoma. ${ }^{37}$ Ultrasound has been suggested to improve the non-invasive diagnosis and offers indeed a high sensitivity $(79 \%$ in our series) for abnormal flow, but lacks specificity for vertebral artery dissection.

The MRI features of vertebral artery dissection have been considered in previous reports. ${ }^{71018}{ }^{22-26}$ An eccentric signal void surrounded by a semilunar hyperintensity on SE images was considered characteristic for a mural haematoma. ${ }^{38}$ This holds true if flow related signal increases due to time of flight effects at entry slices and even echo rephasing phenomena have been excluded by adequate slice positioning or radiofrequency presaturation schemes. The shape of a mural haematoma varies according to the relation between the axis of the affected vessel and the imaging plane. Previous reports have also desribed crescentic, ${ }^{19} 39$ crescent shaped or oval $^{40}$ or circumferential ${ }^{39}$ mural haematomas. A circular increased signal surrounding the lumen of the vertebral artery may suggest vertebral artery dissection, but is not considered a characteristic finding, ${ }^{38}$ even if laminar flow effects are excluded on gradient echo images. Fat suppression techniques have been useful for the differentiation of mural haematomas from surrounding tissues (fig 2). ${ }^{7741}$ Another non-specific finding associated with vertebral artery dissection is poor or absent visualisation of the vertebral artery.

Most reports have focused on mural haematomas in the subacute phase, when methaemoglobin leads to a hyperintense signal on either sequence and therefore is best visualised on MRI. However, the signal behaviour of the mural haematoma changes over time due to the presence of different haemoglobin breakdown products and water content. We found mural haematomas in three patients that were isointense on T1WI, hyperintense on PDWI, and hypointense on T2WI during the acute stage after dissection (fig 2). These haematomas developed the typical high signal intensity due to methaemoglobin formation on follow up examinations.

Most important is the separation of a mural haematoma from a luminal thrombus which 
may be seen in vertebral artery occlusions, caused by different aetiologies. During the acute and subacute phase after dissection, abnormal signal behaviour of the entire lumen of the vertebral artery was seen in 12 of our patients and occurred along with occlusion and thrombosis. SE sequences were unable to differentiate mural from luminal clot formation in occluded vessels ${ }^{38}$ and in cases of high grade stenosis, if residual flow could not be appreciated on SE images. Therefore, a mural haematoma may remain unrecognised unless perpendicular gradient echo sequences through the preoccluded stenotic arterial segment shows a residual patent lumen.

MRA projections and source images were helpful to differentiate residual flow from mural haematoma in four of our patients during the acute stage. Later, when methaemoglobin is present, TOF MRA projections are insufficient to seperate flow from thrombus. The differentiation between mural haematoma and an aneurysmal dilatation, however, is usually possible by reading the source images of the 3D MRA sequence (fig 2). On the MRA projections dissected vessels may appear even wider than the patent lumen if methaemoglobin leads to high signal intensity of the mural haematoma, which is then added to the flow signal of the patent lumen by the maximum intensity projection (MIP) images (fig 3). ${ }^{8}$

A stenosis of a longer vessel segment on MRA is a suggestive finding for vertebral artery dissection in the appropriate clinical context. This finding is not specific and may be difficult to differentiate from hypoplasia, vasospasm, and dysplasia without dissection. This effect appears more prominent on MRA projections, which can be explained by the small diameter and variation in the calibre that leads to signal void due to flow saturation within 3D MRA slabs. ${ }^{42}$ Unlike in DSA, the finding of a stenosis on MRA can become a specific sign, if it is accompanied by a mural haematoma at the coincident level. On this occasion, MRA images should be used to target axial fat suppressed T1WI images (fig 2). A mural haematoma was present on SE and MRA source images in four of our patients as a reliable criterion for vertebral artery dissection. This indicates that MRA is not competitive with DSA, but may disclose complementary information for the diagnosis of vertebral artery dissection.

The direct comparison between DSA and MRA in our series was hampered by the retrospective nature of the investigation. A dissection is an evolving process that may cause rapid lumen obliteration but early recanalisation or slowly progressive mural haematoma are also possible. ${ }^{7}$ The time interval between DSA and MRA were 12 hours to 14 days in 13 patients (14 vertebral artery dissections). The findings of both methods correlated in 10 dissected vertebral arteries. MRA overestimated a stenosis as an occlusion in one patient. It also failed to detect specific features in three patients, in whom DSA disclosed intimal flaps (two) and a double lumen (one) of the V1 segments, that were not included within the MR examination volume. MRA gave additional information in four patients, in whom DSA showed the non-specific finding of a string sign, by delineation of a double lumen in one (fig 1) and visualisation of a mural haematoma in three dissected vertebral arteries (figs 2, 3). MRI/ MRA suggested vertebral artery dissection in six patients before DSA. MRA also provided the diagnosis in a patient who had an occlusion of the V1 segment on DSA, but flow in the V2-3 segments on MRA that resulted from collateralisation via the truncus thyrocervicalis, which had not been injected during DSA. In three patients of this series DSA was not performed, because MRA findings and clinical features were considered conclusive for the diagnosis of vertebral artery dissection.

The optimal timing for follow up examinations has not been defined yet. Sequential ultrasound examination can indicate recanalisation or normalisation of blood flow ${ }^{7}$ and may be helpful for the decision to discontinue anticoagulation therapy. Resolution of the arterial abnormalities is frequent in vertebral artery dissection and therefore short term follow up examinations can support the diagnosis of vertebral artery dissection, if initial results have been non-specific. Although sequential ultrasound examination is a valid method for follow up, MRA may be more useful in delineating complications such as dissecting aneurysms (fig 2).

We started our investigations in 1989 using a coronal 3D TOF MRA examination and confirmed suspicious findings by an additional 2D TOF MRA protocol. According to the higher inflow sensitivity of the transverse $2 \mathrm{D}$ FLASH protocol, we now apply 2D FLASH for the entire course of the vertebral artery using a head/neck coil ${ }^{43}$ that shows the vertebral artery from its origin at the subclavian artery. This reduces the possibility of false negative results secondary to restrictions of the field of view. These recent technological advancies should further improve the diagnostic accurancy of MRI/MRA in vertebral artery dissection.

In conclusion, a combined MRI/MRA examination is recommended as initial neuroradiological investigation in patients with suspected vertebral artery dissection. In our series MRI detected ischaemic lesion in $95 \%$ of the patients. The sensitivity for abnormalities within the vertebral artery was $94 \%$ for MRA. Considering the limitations of a retrospective study, it is beyond the scope of this article to make conclusions about the predictive value of MRI/MRA. However, five specific findings in 17 vertebral artery dissections represent a specificity of $29 \%$, which already approaches the specificity of DSA (35\% (6/17) vertebral artery dissections) in our series. More importantly, the specific results in MRI/MRA and DSA were not obtained in the same patients, which indicates a complementary role for both modalities to improve the overall specificity for vertebral artery dissection (up to $50 \%$ in our series). If MRA yields a double lumen or identifies a mural haematoma, there is no further 
need to perform DSA. If MRA findings do not completely agree with the clinical suspicion or if MRI and MRA findings are doubtful, selective DSA is still the method of choice in the diagnosis of vertebral artery dissection.

1 Hart RG, Easton JD. Dissections. Stroke 1985;16:925-7.

2 Caplan LR, Zarins CK, Hemmatti M. Spontaneous dissection of the extracranial vertebral arteries. Stroke 1985;16: tion of the 8 .

3 Biller J, Hingtgen WL, Adams HP, et al. Cervicocephalic arterial dissections: a ten-year experience. Arch Neurol 1986;43:1234-8.

4 Mas JL, Bousser MG, Hasboun D, et al. Extracranial vertebral artery dissection: a review of 13 cases. Stroke 1987;18. 1037-47.

5 Morki B, Houser OW, Sandok BA, et al. Spontaneous dissections of the vertebral arteries. Neurology 1988;38 $880-5$.

6 Friedman DP, Flanders AE. Unusual dissection of the proximal vertebral artery: description of three cases. AfNR Am $\mathcal{F}$ Neuroradiol 1992;13:283-6.

7 Sturzenegger M, Mattle HP, Rivoir A, et al. Ultrasound findings in spontaneous extracranial vertebral artery dissection. Stroke 1993;24:1910-21.

8 Bui LN, Brant-Zawadzki M, Verghese P, et al. Magnetic resonance angiography of cervicocranial dissection. Stroke 1993;24:126-31.

9 Hinse P, Thie A, Lachenmayer L. Dissection of the extracranial verebral artery: report of four cases and review of the literature. $\mathcal{F}$ Neurol Neurosurg Psychiatry 1991;54:863-9.

10 McCormick GF, Halbach VV. Recurrent ischemic events in two patients with painless vertebral artery dissection. Stroke two patients with p

11 Chiras S, Marciano S, Molina JV, et al. Spontaneous dissecting aneurysm of the extracranial vertebral artery. Neuroradiology 1985;27:327-33.

12 Hart RG. Vertebral artery dissection. Neurology 1988;38: 987-9.

13 Josien E. Extracranial vertebral artery dissection: nine cases. f Neurol 1992;239:327-30.

14 Steinke W, Rautenberg W, Schwartz A, et al. Noninvasive monotoring of internal carotid artery dissection. Stroke 1994;25:998-1055.

15 Smoker WRK, Biller J, Hingtgen WL, et al. Angiography of nonhemorrhagic cerebral infarction in young adults. Stroke 1987;18:708-11.

16 Hankey GJ, Warlow CP, Sellar RJ. Cerebral angiographic risk in mild cerebrovascular disease. Stroke 1990;21:20922 .

17 Brugieres P, Castrec-Carpo A, Heran F. Magnetic resonance imaging in the exploration of dissection of internal carotid artery. $f$ Neuroradiol 1989;16:1-10.

18 Gelbert F, Assouline E, Hodes JE, et al. MRI in spontaneous of vertebral and carotid arteries: 15 cases studied at 0,5 tesla. Neuroradiology 1991;33:111-3.

19 Goldberg HI, Grossmen R, Gomori J, et al. Cervical internal carotid artery dissecting hemorrhage: diagnosis using MRI Radiology 1986;158:157-61.

20 Hennerici M, Steinke W, Rautenberg W. High-resistance Doppler-flow pattern in extracranial carotid dissection. Arch Neurol 1989;46:670-6.

21 Rothrock JF, Lim V, Press G, et al. Serial magnetic resonance and carotid duplex examination in the management of carotid dissection. Neurology 1989;39:686-92.

22 Sue DE, Brant-Zawadzki MN, Chance JTI. Dissection of cranial arteries in the neck: correlation of MRI and arteriography. Neuroradiology 1992;34:273-8.
23 Lévy C, Laissy JP, Raveau V, et al. Carotid and vertebral artery dissections: three-dimensional time-of-flight MR angiography and MR imaging versus conventional angiography. Radiology 1994;190:97-103.

24 Chen J, Smith R, Keller A, et al. Spontaneous dissection of the vertebral artery: MR findings. F Comput Assist Tomogr 1989;13:326-9.

25 Mas JL, Bousser MG, Touboul PJ. Extracranial vertebral artery dissection. $\mathcal{F}$ Neurol Neurosurg Psychiatry 1992;55: 979-80.

26 Quint DJ, Spickler EM. Magnetic resonance demonstration of vertebral artery dissection: report of two cases. 7 Neurosurg 1990;72:964-7.

27 Röther J, Schwartz A, Rautenberg W, et al. Magnetic resonance angiography of spontaneous vertebral artery dissection suspected on Doppler ultrasonography. $\mathcal{F}$ Neurol 1995;242:430-6.

28 Hoffmann M, Sacco RL, Chan S, et al. Noninvasive detection of vertebral artery dissection. Stroke 1993;24: $815-9$.

29 Felber S, Chemelli A, Posch A, et al. 3D-time of flight magnetic resonance angiography in cerebrovascular diseases. In: Aichner F, Felber S, Müller R, et al, eds. 3D magnetic resonance imaging, techniques and clinical impact. London: Blackwell 1994:227-46.

30 Ruggeri PM, Laub P, Masaryk TJ, et al. Intracranial circulation: pulse sequence considerations in threedimensional (volume) angiography. Radiology 1989;171: 785-91.

31 Argenson C, Francke JP, Sylla S, et al. The vertebral arteries (segments V1 and V2). Anat Clin 1980;2:29-41.

32 Francke JP, di Marino V, Pannier M, et al. The vertebral arteries (arteria vertebralis). The V3 atlanto-axial and V4 intracranial segments-collaterals. Anat Clin 1981;2:22942.

33 Fisher CM, Ojemann RG, Robertson GH. Spontaneous dissection of the cervico-cerebral arteries. Can $\mathcal{F} \mathrm{Neurol} \mathrm{Sci}$ 1978;5:9-19.

34 Miyazaki S, Yamura A, Kamata K, et al. A dissecting aneurysm of the vertebral artery. Surg Neurol 1984;21:171-4.

35 Alom J, Matias -Guiu J, Prado L, et al. Spontaneous dissection of intracranial vertebral artery: clinical recovery with conservative treatment. F Neurol Neurosurg Psychiatry 1986; 49:599-612.

36 Waga S, Fujimoto K, Morooka Y. Dissecting aneurysm of the vertebral artery. Surg Neurol 1978;10:237-9.

37 Kitanaka C, Tanaka J, Kuwahara M, et al. Magnetic resonance imaging study of intracranial vertebrobasilar artery dissections. Stroke 1994;25:571-5.

38 Zuber M, Meary E, Meder JF, et al. Magnetic resonance imaging and dynamic CT scan in cervical artery dissections. Stroke 1994;25:576-81.

39 Tobias JA. MRI of intracranial vascular disease with emphasis at low and intermediate field strengths (images at 0.351.0 T). In: Pomeranz SJ, ed. Craniocervical magnetic resonance imaging. Philadelphia: WB Saunders, 1989:31550 .

40 Iwama T, Andoh T, Sakai N, et al. Dissecting and fusiform aneurysms of vertebro-basilar systems: MR imaging. Neuroradiology 1990;32:272-9.

41 Pacini R, Simon J, Ketonen L, et al. Chemical shift imaging of a spontaneous internal carotid artery dissection: case report. AfNR Am f Neuroradiol 1991;12:360-2.

42 Anderson CM, Saloner D, Tsuruda JS, et al. Artefacts in maximum-intensity-projection display on $\mathrm{MR}$ angiograms. AfR Am f Roentgenol 1990;154:623-9.

43 Anderson CM, Saloner D, Lee R, et al. Dedicated coil for carotid MR-angiography. Radiology 1990;176:868-72. 